\title{
Characterization of Microstructure and Mechanical Properties of Ti-6Al-4V Alloy after Cyclic Heat Treatment
}

\author{
Zhixiong ZHANG ${ }^{1,2,3 *}$, Ruirui WU $^{4}$, Jie HOU ${ }^{4}$, Tao WANG ${ }^{1,2,3}$ \\ ${ }^{1}$ College of Mechanical and Vehicle Engineering, Taiyuan University of Technology, Taiyuan 030024, China \\ ${ }^{2}$ Engineering Research Center of Advanced Metal Composites Forming and Equipment, Ministry of Education, Taiyuan \\ 030024 , China \\ ${ }^{3}$ TYUT-UOW Joint Research Centre, Taiyuan 030024, China \\ ${ }^{4}$ Instrumental analysis center, Taiyuan University of Science and Technology, Taiyuan 030024, China \\ crossref http://dx.doi.org/10.5755/j02.ms.23023
}

Received 25 March 2019; accepted 10 July 2019

\begin{abstract}
A cost-effective approach which consists of cyclic heat treatment (CHT) and annealing is used to refine the coarse lamellar structure of as-cast Ti-6Al-4V alloy. The coarse lamellar microstructure was significantly refined after the CHT process, $\alpha$ lamellae were broken up while the original orientations of $\alpha$ lamellae were maintained. After annealing treatment, a basketweave microstructure was achieved in Ti-6Al-4V alloy, and the formation of globular $\alpha$ grains was observed. The microstructure refinement mechanisms during CHT and annealing are mainly considered to be break-up of lamellar structure and static recrystallization. The room temperature mechanical properties of Ti-6Al-4V alloy were significantly improved. The microhardness of Ti-6Al-4V alloy increased from $306 \mathrm{HV}$ to $402 \mathrm{HV}$. The values of yield strength (YS) and ultimate tensile strength (UTS) increased from $734 \mathrm{MPa}$ and $740 \mathrm{MPa}$ to $911 \mathrm{MPa}$ and $1010 \mathrm{MPa}$, respectively. The value of ductility increased from $1.1 \%$ to $3.3 \%$.

Keywords: Ti-6Al-4V, cyclic heat treatment, microstructure refinement, static recrystallization.
\end{abstract}

\section{INTRODUCTION}

Ti-6Al-4V is the most widely used titanium alloy in aerospace, automotive and medical implant industries due to its excellent comprehensive properties, such as high specific strength, superior corrosion resistance and good elevated temperature performance $[1,2]$. Ti-6Al-4V alloy is commonly produced by ingot metallurgy, the as cast ingots exhibit a lamellar structure [3,4]. The initial lamellar microstructure is one of the typical microstructures of Ti$6 \mathrm{Al}-4 \mathrm{~V}$ alloy, this microstructure exhibits moderate strength and high fatigue crack growth resistance but extralow ductility [5]. The breakdown of lamellar structure after hot working or heat treatment plays a key role in the production of mill products of $\alpha / \beta$ titanium alloys [6].

Thermomechanical processing is the most effective way to control the microstructure [7]. Numerous studies have indicated that the $\alpha / \beta$ titanium alloys with a fine microstructure possess both high strength and good ductility [8-12]. Generally, thermomechanical processing of $\alpha / \beta$ titanium ingots involves a series of steps to modify the ascast microstructure to obtain an equiaxed microstructure. These include $\beta$ hot working and $\beta$ annealing to refine $\beta$ grain structure and the sub-transus hot working to break down the transformed microstructure [13-16].

Currently, it is significant to seek a simple way to improve the comprehensive mechanical properties through controlling the microstructure. As reported by J.N. Wang [17-19], the fully lamellar structure of TiAl alloys could be effectively refined merely by cyclic heat treatment (CHT). Koscielna also reported that [20] the influence of individual parameters of a cyclic heat treatment on the grain refinement of a Ti-48Al-2Cr-2Nb alloy with a coarse-grained microstructure, the mechanical properties of the alloy were also improved. Similarly, it is hoped that the initial coarse lamellar structure of Ti-6Al-4V could be refined through $\mathrm{CHT}$ process. And the studies about refining the coarse lamellar structure of Ti-6Al-4V alloy through CHT are limited. The microstructure evolution and grain refinement mechanism are not clear and needed to be studied deeply.

In this study, we report an alternative method by which the initial coarse lamellar structure of as-cast Ti-6Al-4V alloy can be refined merely by CHT. The microstructure evolution and mechanical properties enhancement of $\mathrm{Ti}$ 6Al-4V alloy during CHT process are investigated, and the grain refinement mechanism of $\mathrm{Ti}-6 \mathrm{Al}-4 \mathrm{~V}$ alloy during CHT process is to be clarified.

\section{MATERIALS AND METHODS}

The extra-low interstitial (ELI) grade Ti-6Al-4V alloy having the following chemical composition (wt.\%) was used in this study: $6.08 \mathrm{Al}, 4.03 \mathrm{~V}, 0.14 \mathrm{Fe}, 0.013 \mathrm{Si}$, $0.018 \mathrm{C}, 0.11 \mathrm{O}, 0.0047 \mathrm{~N}, 0.0008 \mathrm{H}$ and balanced Ti. The $\beta$ transus temperature for this grade is approximately $975{ }^{\circ} \mathrm{C}$. As received Ti-6Al-4V cylinder with a diameter of $355 \mathrm{~mm}$ was produced by ingot metallurgy.

Specimens with a dimension of $10 \times 8 \times 6 \mathrm{~mm}^{3}$ were cut from the as received ingots by electro-discharge machining (EDM). The as received Ti-6Al-4V alloy was subjected to a $\beta$ heat treatment at $1015^{\circ} \mathrm{C}$ for $1 \mathrm{~h}$ to homogenize the microstructure and elements distribution. After the

\footnotetext{
* Corresponding author. Tel.: +86-19834438583.

E-mail address: zhangzhixiong@tyut.edu.cn (Z.X. Zhang)
} 
homogenization treatment, the alloy was furnace cooling to $955^{\circ} \mathrm{C}$ and subjected to CHT. In one cycle, the specimens were heated to $955^{\circ} \mathrm{C}$ and soaked for $10 \mathrm{~min}$, and then furnace cooled to $650{ }^{\circ} \mathrm{C}$ and soaked for $10 \mathrm{~min}$. The CHT process consisted of 5 cycles, and after $\mathrm{CHT}$, the specimens were water quenched (WQ) to maintain the fine microstructure developed during the CHT process (Fig. 1). In addition, an annealing treatment was conducted in a $\mathrm{SiC}$ box furnace at $500{ }^{\circ} \mathrm{C}$ for $4 \mathrm{~h}$ followed by air cooling (AC).

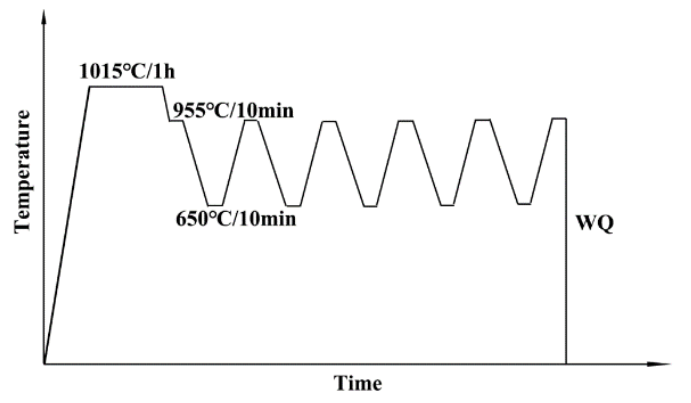

Fig. 1. Schematic diagram of CHT process

The microstructure examinations of specimens were performed by optical microscopy (OM, MF-DS), scanning electron microscopy (SEM, FEI Quanta 250 FEG), and transmission electron microscopy (TEM, JEOL JEM$2100 \mathrm{~F}$ ). The specimens for OM and SEM characterization were electrochemically polished by using a solution of $60 \%$ methanol, $34 \%$ n-butanol and $6 \%$ perchloric acid with an applied current of $80 \mathrm{~mA}$ at $-30{ }^{\circ} \mathrm{C}$. The TEM foils were twin-jet electrochemically polished at $30 \mathrm{~V}$ and $-30^{\circ} \mathrm{C}$.

Tensile tests were conducted on the Zwick Z100 servohydraulic testing system with a starting strain rate of $10^{-3} \mathrm{~s}^{-1}$ at ambient temperature. Plate specimens were employed with a gauge length of $16 \mathrm{~mm}$ and a width of $4 \mathrm{~mm}$ and a thickness of $2 \mathrm{~mm}$. Wedge grips were used to mount the specimens. Contact extensometers were used for extension measurement. Vickers hardness measurements were performed by applying a load of $500 \mathrm{~g}$ for $15 \mathrm{~s}$. The specimens for microhardness test were electrochemically polished.

\section{RESULTS AND DISCUSSION}

The lamellar starting structure has Widmannstätten morphology, which is shown in Fig. 2. The Widmannstätten structure consists of lamellar $\alpha$ colonies in initial $\beta$ grains of the order of mm and a grain boundary $\alpha$ phase layer of about $5 \mathrm{~mm}$ thick. The thickness of $\alpha$ lamellae inside $\beta$ grains is about $3 \mu \mathrm{m}$ and the continuous $\beta$ layers distributed between lamellar $\alpha$ structure are about $1 \mu \mathrm{m}$ thick.

Fig. 3 shows the microstructure after 5 cycles CHT. From Fig. 3, it can be seen that $\alpha$ lamellae were broken up during the CHT process. The retained lamellar $\alpha$ segments appeared in the transformed $\beta$ matrix and were parallel to each other. The original orientations of $\alpha$ lamellae were maintained. It was obvious that the coarse lamellar microstructure was significantly refined during the CHT process.

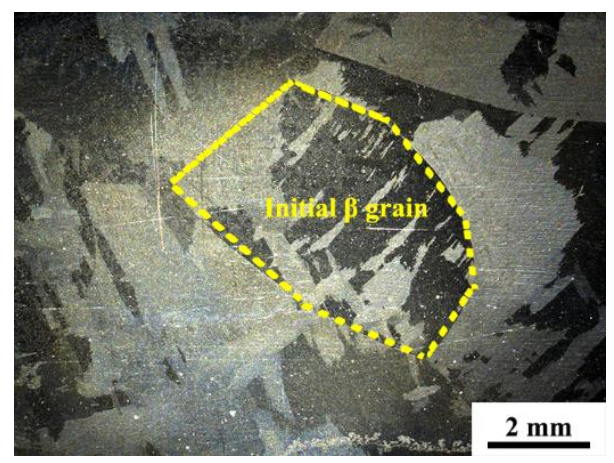

a

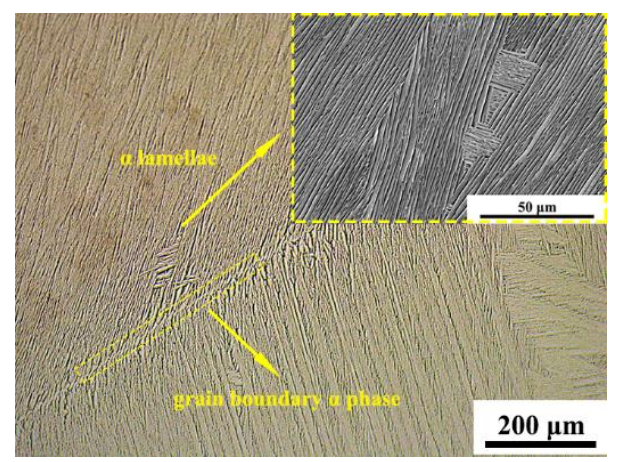

b

Fig. 2. As received Ti-6Al-4V alloy: $a-$ macro picture; $b-O M$ image

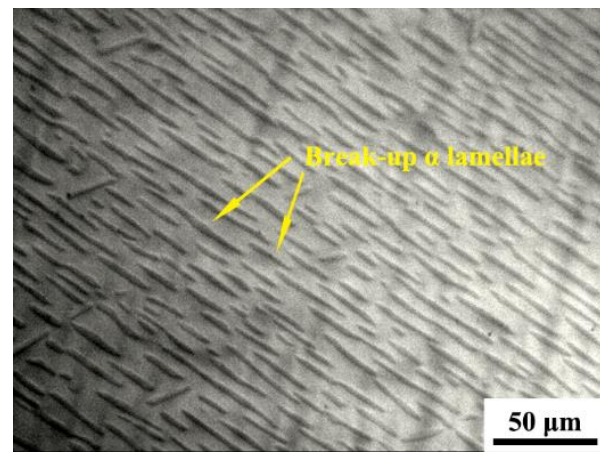

a

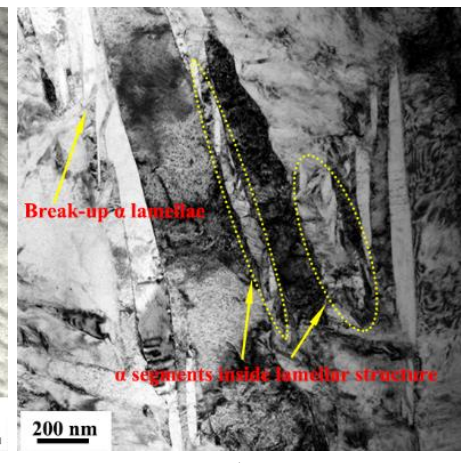

b

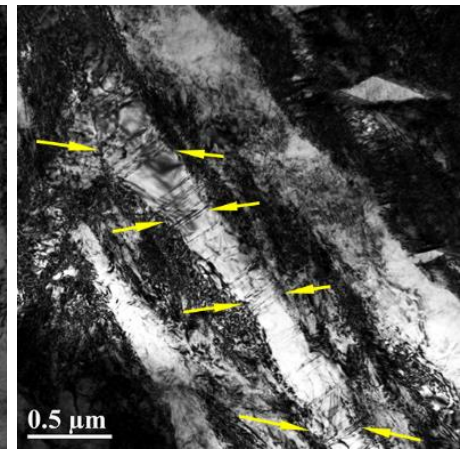

c

Fig. 3. Microstructure of Ti-6Al-4V alloy after 5 cycles CHT: a-break-up of $\alpha$ lamellae; $\mathrm{b}-\alpha$ segments inside the lamellar $\alpha$ structure; $\mathrm{c}$-dislocations inside $\alpha$ lamellae 
Microstructure evolution during 5 cycles CHT process was further elucidated by transmission electron microscopy (TEM), as shown in Fig. 3 b and c). From Fig. 3 b, it could be seen that the original $\alpha$ lamellae broke up into small $\alpha$ segments. Furthermore, substructures were also formed within the lamellar $\alpha$ plates. Besides, high density dislocations were observed in $\alpha$ phases, and dislocation pileups formed in some of the lamellar $\alpha$ phases (Fig. 3 c). Dislocations slipping across $\alpha$ plates indicated that the break-up process of lamellar $\alpha$ phase was driven by dislocation motion. Microstructure observation results showed the break-up of the prior $\alpha$ lamella due to CHT, and the orientation of $\alpha$ lamella was maintained. The microstructure refinement mechanism during CHT can be explained by the following procedures: (i) at the heating stage of CHT process, the prior $\alpha$ lamellae dissolved and transformed to $\beta$ phase, the dissolution of $\alpha$ phase preferred to occur in the grooves of $\alpha$ plates, the long $\alpha$ plates were fragmented into several small segments. Because the heating temperature was below the $\beta$ transus temperature, $\alpha$ lamellae could not be dissolved totally, several segments of prior $\alpha$ lamella were retained. (ii) at the cooling stage, due to the heredity of Widmannstätten structure, $\alpha$ phase separated out from the retained $\alpha$ segments and grew up following the original orientation of prior $\alpha$ lamellae. When $\alpha$ lamellae grew to touch each other, they could not fuse completely, remaining an interface between each other. As a consequence, the prior $\alpha$ lamella transformed into several small pieces. With the CHT cycles increasing, the fragmentation process of prior $\alpha$ lamella was finished completely, the refinement of microstructure was more effectively. The founder effect of this fragmentation mechanism is the dissolution and precipitation of $\alpha$ phase. Thus, the upper heating temperature and the temperature interval are two key points for the CHT process. If the upper heating temperature is too high to exceed the $\beta$ transus temperature, $\alpha$ phase will dissolved completely, and the Widmannstätten structure will be obtained as before. On the contrary, if the upper heating temperature is too low, atoms are less mobile and difficult to diffuse, the fragmentation of $\alpha$ lamellae can not be finished completely.

After 5 cycles CHT, the specimens were subjected to an annealing process at the temperature of $500{ }^{\circ} \mathrm{C}$ for $4 \mathrm{~h}$. During the annealing process, the primary $\alpha$ phases grew up to some extent, the annealing treatment produced thickening of $\alpha$ plates. Besides, some of the transformed $\beta$ microstructure transformed into the secondary $\alpha$ phases, and the secondary $\alpha$ plates appeared on the transformed $\beta$ matrix to form basket weave structure with the primary $\alpha$ phases

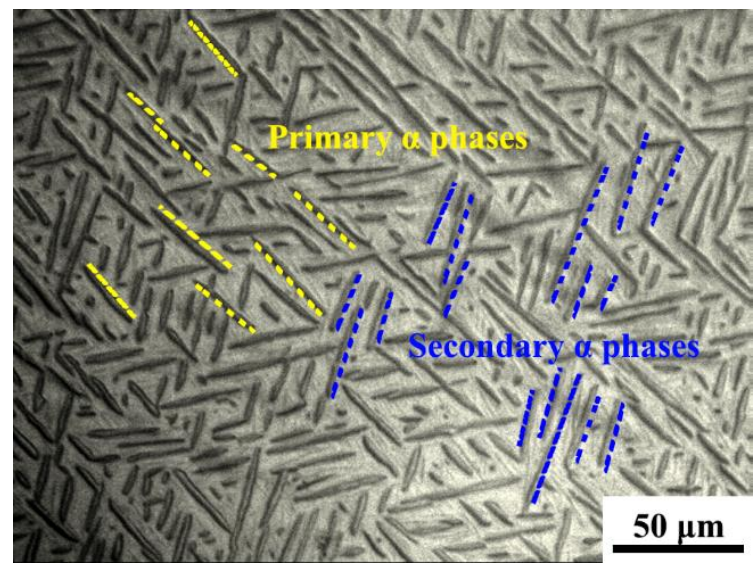

a
(Fig. 4 a). Furthermore, the annealing treatment led to noticeable globularization of $\alpha$ segments, the formation of globular $\alpha$ grains was observed (Fig. 4 b).

Similarly, microstructure evolution during annealing process was studied deeply through TEM observation. As shown in Fig. $5 \mathrm{a}$ and $\mathrm{b}, \alpha$ lamellae with different orientations intersected each other to form a basketweave microstructure. Furthermore, the dislocation density decreased considerably, grain and interphase boundaries became clear, suggesting a recovery process occurred during annealing process. In addition, static globularization process of $\alpha$ phase was also observed (Fig. 5 c, d). Large size globular $\alpha$ grains were formed (Fig. $5 \mathrm{c}$ ), a recrystallized microstructure comprised of equiaxed grains with a grain size of $0.3 \sim 0.5 \mu \mathrm{m}$ was observed (Fig. $5 \mathrm{~d}$ ), the overall microstructure was refined considerably.

During the early stage of annealing treatment, a recovery process occurred firstly, the dislocations and substructures were eliminated. Thus, the dislocation density was low after annealing. Furthermore, the substructures and retained $\alpha$ segments were highly developed during heat treatment. Dynamic coarsening of $\alpha$ phase occurred with the soaking time increasing [22]. The secondary $\alpha$ phases separated out and developed to form intersect structure. A number of retained $\alpha$ segments grew up to high aspect ratio lamellar $\alpha$ structure.

Another important microstructural changes occurred during annealing is the globularization of $\alpha$ phase. According to Stefansson [23], the process of static globularization was merely partly dependent on the formation and development of dislocation substructures. Generally, globularization process of lamellar structure was considered to be dynamic recrystallization (DRX) [24].

From Fig. 5 c, a very large dislocation-free particle of $\alpha$ phase was observed. And as shown in Fig. $5 \mathrm{~d}$, a recrystallized microstructure with a grain size of $0.5 \mu \mathrm{m}$ was formed. Several investigations [5, 7, 23, 25, 26] have given insight into the mechanisms of globularization of lamellar $\alpha$ during heat treatment. Two ways of the lamellae globularization were provided. Both involve boundary splitting resulting from the creation of boundaries across the lamellar structure. In one case, $\alpha / \alpha$ boundaries are rooted in the formation of a recovered substructure [23].

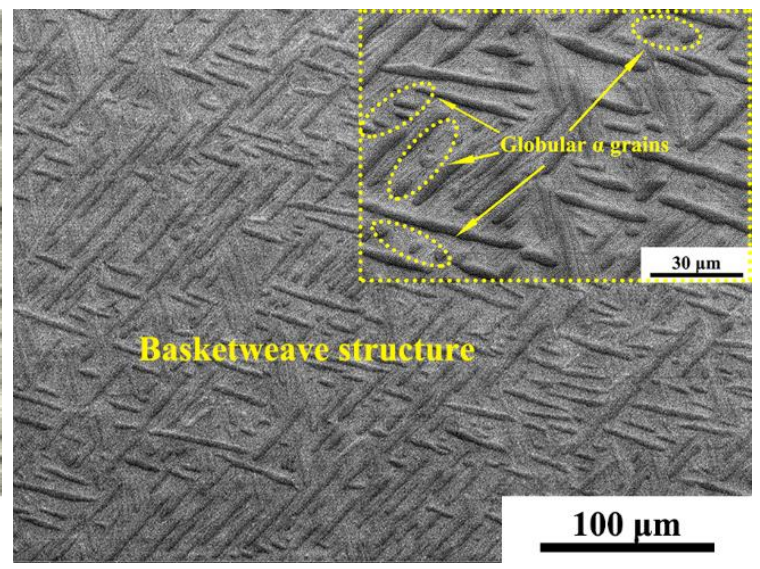

$\mathrm{b}$

Fig. 4. Microstructures of Ti-6Al-4V alloy after 5 cycles CHT and annealing: a-OM image; $b-$ SEM image 


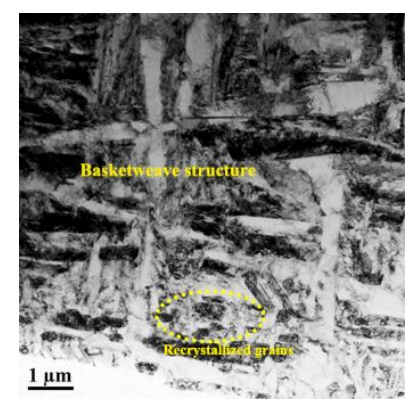

a

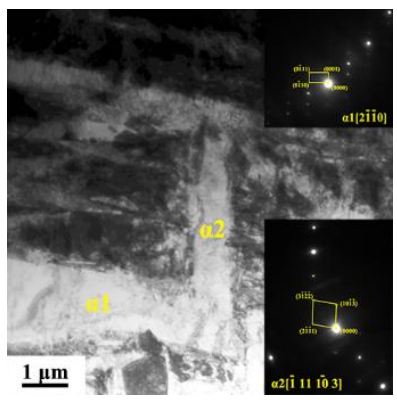

b

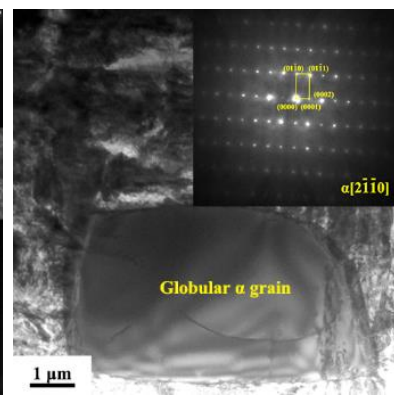

c

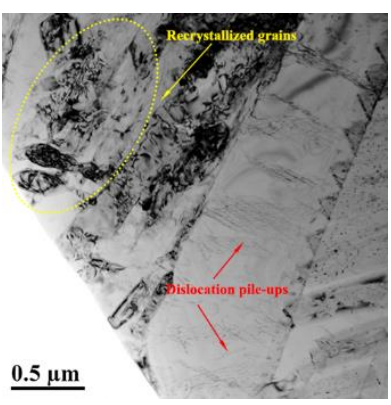

d

Fig. 5. TEM image of basketweave microstructure of Ti-6Al-4V alloy after annealing: $a$-basketweave microstructure; $b$-intersect $\alpha$ plates; $\mathrm{c}$-globular $\alpha$ grain; $\mathrm{d}$-recrystallized grains

And in the other, the boundaries derive from the intense localized shear bands due to deformation [5]. As a consequence, the microstructure was significantly refined.

The room-temperature mechanical properties of the Ti6Al-4V alloy are given in Table 1.

Table 1. Room-temperature mechanical properties of Ti-6Al-4V alloy in different conditions

\begin{tabular}{|l|c|c|c|c|c|}
\hline Conditions & $\begin{array}{c}\text { Microhardness, } \\
\mathrm{HV}\end{array}$ & $\begin{array}{c}\text { YS, } \\
\mathrm{MPa}\end{array}$ & $\begin{array}{c}\text { UTS, } \\
\mathrm{MPa}\end{array}$ & El, \% & $\begin{array}{c}\text { AR, } \\
\%\end{array}$ \\
\hline As-received & 306 & 734 & 740 & 1.1 & 12 \\
\hline CHT+annealing & 402 & 911 & 1010 & 3.3 & 34 \\
\hline
\end{tabular}
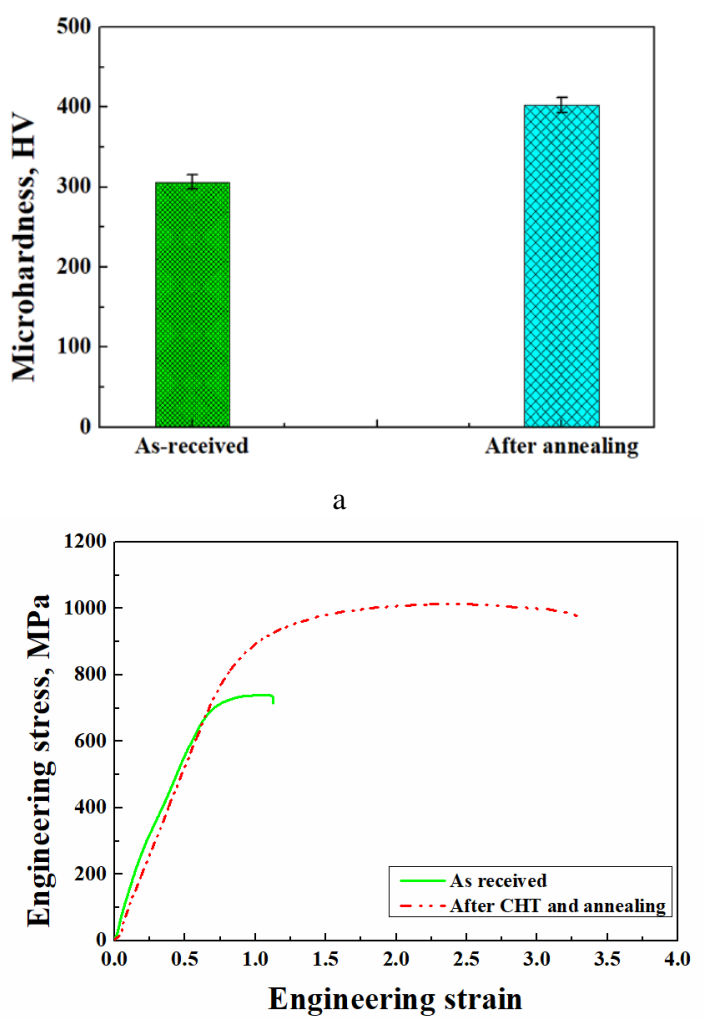

$\mathrm{b}$

Fig. 6. Mechanical properties of Ti-6Al-4V alloy before and after $\mathrm{CHT}$ and annealing process: $\mathrm{a}-$ microhardness; $\mathrm{b}$-tensile engineering strain-engineering stress curves

The evolution of microhardness is shown in Fig. 6 a, and the tensile engineering stress-strain curves are shown in Fig. 6 b. From Table 1, after the CHT and annealing process, the microhardness of Ti-6Al-4V alloy increased from $306 \mathrm{HV}$ to $402 \mathrm{HV}$. The room temperature tensile test results indicated that the values of YS and UTS increased from $734 \mathrm{MPa}$ and $740 \mathrm{MPa}$ to $911 \mathrm{MPa}$ and $1010 \mathrm{MPa}$, respectively. The value of ductility increased from $1.1 \%$ to $3.3 \%$.

\section{CONCLUSIONS}

Ti-6Al-4V alloy with a lamellar structure are investigated. The following conclusions can be draw:

1. During CHT process, $\alpha$ lamellae were broken up and parallel to each other, the original orientations of $\alpha$ lamellae were maintained.

2. During annealing, the secondary $\alpha$ phases separated out and developed to form basketweave structure with primary $\alpha$ phases, meanwhile, the substructures of $\alpha$ phase developed into recrystallized grains.

3. After CHT and annealing process, a basketweave microstructure was achieved, and the microstructure was significantly refined. The microstructure refinement mechanisms are mainly considered to be break-up of lamellar structure and static recrystallization.

4. The room temperature mechanical properties of Ti-6Al$4 \mathrm{~V}$ alloy were significantly improved after $\mathrm{CHT}$ and annealing process.

\section{Acknowledgments}

The authors are grateful for the financial support provided by the National Natural Science Foundation of China (NSFC) (Grant Nos. 51901151, U1710254, 51701116 and 51804215); Taiyuan city science and technology major projects (Grant Nos. 170203) and Shanxi province science and technology major projects (Grant Nos. 20181102015) and Scientific and Technological Innovation Programs of Higher Education Institutions in Shanxi Province (STIP) (Grant Nos. 2019L0338) and China Postdoctoral Science Foundation (Grant Nos. 2020M680918).

\section{REFERENCES}

1. Leyens, C., Peters, M. Titanium and Titanium Alloys, Wiley-VCH Verlag GmbH, Cologne, 2003: pp. 1-532.

2. Zhang, Z., Qu, S., Feng, A., Hu, X., Shen, J. Microstructural Mechanisms during Multidirectional Isothermal Forging of As-cast Ti-6Al-4V Alloy with an Initial Lamellar Microstructure Journal of Alloys and Compounds 773 2019: pp. 277-287. 
https://doi.org/10.1016/j.jallcom.2018.09.220

3. Lutjering, G., Williams, J. Titanium. 2nd ed. Springer, Berlin, 2007: pp. 1-449.

4. Zhang, Z., Qu, S., Feng, A., Hu, X., Shen, J. The Low Strain Rate Response of As-Cast Ti-6Al-4V Alloy with an Initial Coarse Lamellar Structure Metals 8 (4) 2018: pp. $1-13$.

https://doi.org/10.3390/met8040270

5. Zherebtsov, S., $\quad$ Murzinova, M., $\quad$ Salishchev, G., Semiatin, S. Spheroidization of the Lamellar Microstructure in Ti-6Al-4V Alloy during Warm Deformation and Annealing Acta Materialia 59 (10) 2011: pp. $4138-4150$.

https://doi.org/10.1016/j.actamat.2011.03.037

6. Shell, E., Semiatin, S. Effect of Initial Microstructure on Plastic Flow and Dynamic Globularization during Hot Working of Ti-6Al-4V Metallurgical and Materials Transactions A 30 (12) 1999: pp. 3219-3229. https://doi.org/10.1007/s11661-999-0232-4

7. Weiss, I., Froes, F., Eylon, D., Welsch, G. Modification of Alpha Morphology in Ti-6Al-4V by Thermalmechanical Processing Metallurgical Transactions A 17A 1986: pp. 1935 - 1947. https://doi.org/10.1007/BF02644991

8. Brun, M., Anoshkin, N., Shakhanova, G. Physical Processes and Regimes of Thermomechanical Processing Controlling Development of Regulated Structure in the Alpha+Beta Titanium Alloys Materials Science and Engineering A $243(1-2)$ 1998: pp. 77-81. https://doi.org/10.1016/S0921-5093(97)00781-8

9. Prasad, Y., Seshacharyulu, T. Processing Maps for Hot Working of Titanium Alloys Materials Science and Engineering A 243 (1-2) 1998: pp. 82-88. https://doi.org/10.1016/S0921-5093(97)00782-X

10. Semiatin, S., Goetz, R., Shell, E., Seetharaman, V., Ghosh, A. Cavitation and Failure during Hot Forging of Ti6Al-4V Metallurgical and Materials Transactions A 30 (5) 1999: pp. $1411-1424$. https://doi.org/10.1007/s11661-999-0289-0

11. Zhang, W., Ding, H., Pereira, P., Huang, Y., Langdon, T. Grain Refinement and Superplastic Flow in a Fully Lamellar Ti-6Al-4V Alloy Processed by High-pressure Torsion Materials Science and Engineering: A 732 2018: pp. 398-405. https://doi.org/10.1016/j.msea.2018.07.010

12. Zhang, Z., Qu, S., Feng, A., Shen, J. Achieving Grain Refinement and Enhanced Mechanical Properties in Ti-6Al4V alloy Produced by Multidirectional Isothermal Forging Materials Science and Engineering: A 692 2017: pp. $127-138$. https://doi.org/10.1016/j.msea.2017.03.024

13. Weiss, I., Semiatin, S. Thermomechanical Processing of Alpha Titanium Alloys - An Overview Materials Science and Engineering A 263 (2) 1999: pp. 243-256. https://doi.org/10.1016/S0921-5093(98)01155-1

14. Prasad, Y., Seshacharyulu, T., Medeiros, S., Frazier, W. A Study of Beta Processing of Ti-6Al-4V: Is it trivial? Journal of Engineering Materials and TechnologyTransactions of the Asme 123 (3) 2001: pp. 355-360. https://doi.org/10.1115/1.1372708
15. Seshacharyulu, T., Medeiros, S., Frazier, W., Prasad, Y. Microstructural Mechanisms during Hot Working of Commercial Grade Ti-6Al-4V with Lamellar Starting Structure Materials Science and Engineering A $325(1-2)$ 2002: pp. $112-125$. https://doi.org/10.1016/S0921-5093(01)01448-4

16. Zhang, Z., Qu, S., Feng, A., Shen, J., Chen, D. Hot Deformation Behavior of Ti-6Al-4V alloy: Effect of Initial Microstructure Journal of Alloys and Compounds 718 2017: pp. $170-181$ https://doi.org/10.1016/j.jallcom.2017.05.097

17. Wang, J., Xie, K. Refining of Coarse Lamellar Microstructure of TiAl Alloys by Rapid Heat Treatment Intermetallics 8 (5) 2000: pp. 545-548. https://doi.org/10.1016/S0966-9795(99)00153-3

18. Yang, J., Wang, J., Xia, Q., Wang, Y. Effect of Cooling Rate on the Grain Refinement of TiAl-based Alloys by Rapid Heat Treatment Materials Letters 46 (4) 2000: pp. $193-197$. https://doi.org/10.1016/S0167-577X(00)00167-1

19. Yang, J., Wang, J., Wang, Y., Xia, Q., Zhang, B. Control of the Homogeneity of the Lamellar Structure of a TiAl Alloy Refined by Heat Treatment Intermetallics 9(5) 2001: pp. 369-372. https://doi.org/10.1016/S0966-9795(01)00020-6

20. Kościelna, A., Szkliniarz, W. Effect of Cyclic Heat Treatment Parameters on the Grain Refinement of Ti-48Al$2 \mathrm{Cr}-2 \mathrm{Nb}$ Alloy Materials Characterization $60(10)$ 2009: pp. $1158-1162$. https://doi.org/10.1016/j.matchar.2009.03.008

21. Obasi, G., Birosca, S., Leo Prakash, D., Quinta da Fonseca, J., Preuss, M. The Influence of Rolling Temperature on Texture Evolution and Variant Selection during $\alpha \rightarrow \beta \rightarrow \alpha$ Phase Transformation in Ti-6Al-4V Acta Materialia 60 (17) 2012: pp. 6013-6024. https://doi.org/10.1016/j.actamat.2012.07.025

22. He, L., Dehghan-Manshadi, A., Dippenaar, R. The Evolution of Microstructure of Ti-6Al-4V Alloy during Concurrent Hot Deformation and Phase Transformation Materials Science and Engineering: A 549 2012: pp. $163-167$ https://doi.org/10.1016/j.msea.2012.04.025

23. Stefansson, N., Semiatin, S. Mechanisms of Globularization of Ti-6Al-4V during Static Heat Treatment Metallurgical and Materials Transactions A 34 (3) 2003: pp. $691-698$. https://doi.org/10.1007/s11661-003-0103-3

24. Seshacharyulu, T., Medeiros, S., Morgan, J., Malas, J., Frazier, W., Prasad, Y. Hot Deformation Mechanisms in ELI Grade Ti-6Al-4V Scripta Materialia 41 (3) 1999: pp. $283-288$. https://doi.org/10.1016/S1359-6462(99)00163-3

25. Stefansson, N., Semiatin, S., Eylon, D. The Kinetics of Static Globularization of Ti-6Al-4V Metallurgical and Materials Transactions A 33 (11) 2002: pp. 3527-3534. https://doi.org/10.1007/s11661-002-0340-x

26. Semiatin, S., Stefansson, N., Doherty, R. Prediction of the Kinetics of Static Globularization of Ti-6Al-4V Metallurgical and Materials Transactions A 36 (5) 2005: pp. $1372-1376$. https://doi.org/10.1007/s11661-005-0229-6 